\title{
AND TELL SAD STORIES OF THE DEATH OF QUEENS: O CAMP E A METÁFORA DA VIDA COMO TEATRO
}

\author{
And tell sad stories of the death of queens: the \\ camp and the metaphor of life as theater
}

\author{
DJALMa ThürLeR ${ }^{1}$ \\ ${ }^{1}$ Universidade Federal da Bahia. Salvador, Bahia, Brasil. \\ E-mail: djalmathurler@uol.com.br
}

\section{RESUMO}

Este artigo se debruça sobre o texto de teatro And Tell Sad Stories of the Deaths of Queens, de Tennessee Williams, e procura demonstrar a consciência do autor sobre o camp e intenta discutir a tradução da expressão queen e suas implicações no casting da personagem Candy na cena contemporânea. Este ensaio baseia-se em perspectivas críticas queer e em saberes de desaprendizagem para enfatizar as formas como Williams encena a homossexualidade como um elemento estético da peça.

PALAVRAS-CHAVE: teatro, dramaturgia, Tennessee Williams, camp, crítica queer.

EDITOR-CHEFE:

Gerson Roberto Neumann

EDITOR EXECUTIVO:

Regina Zilberman

SUBMETIDO: 30.04 .2021

ACEITO: 15.06 .2021

\section{COMO CITAR:}

THÜRLER, Djalma. And tell sad stories of the death of queens: o camp e a metáfora da vida como teatro. Revista Brasileira de Literatura Comparada, v. 23 , n. 44 , p. 177-191, set.dez., 2021. doi: https:// doi.org/10.1590/2596304x20212344dt

\section{ABSTRACT}

This article delves into Tennessee Williams' theater text And Tell Sad Stories of the Deaths of Queens and seeks to demonstrate the author's awareness of camp and attempts to discuss the translation of the term queen and its implications for the casting of the character Candy in the contemporary scene. This essay draws on critical queer perspectives and unlearning knowledges to emphasize the ways in which Williams stages homosexuality as an aesthetic element in the play.

KEYWORDS: theater, dramaturgy, Tennessee Williams, camp, queer criticism. 


\section{You can't expect me to seriously believe that a man who has been shipping in and out of \\ New Orleans for five years is still not able to recognize a queen in a gay bar. [Candy, And Tell Sad Stories of the Deaths of Queens (2005)]}

A nd Tell Sad Stories of the Deaths of Queens, traduzida no Brasil por E Contar tristes histórias das mortes das bonecas (2011) é uma das várias peças de teatro de um único ato de Tennessee Williams (1911-1983) 1 publicadas e produzidas postumamente e que foi, apenas recentemente, oferecida ao público. Sua história gira em torno de Candy Delaney, que vai a um bar gay e, por desejo e solidão, leva para casa um jovem da marinha mercante que acabara de conhecer, Karl - ostensiva e imponentemente heterossexual -, cujo caráter nos lembra Stanley Kowalski por sua presença ameaçadora a Blanche DuBois. Karl é um homem forte, assustador e sexy, características suficientes para compreendermos por que é que Candy mantém este homem perigoso e rude por perto. Daí em diante, Candy encena um impressionante retrato de amor não correspondido.

Sua primeira encenação se deu em 28 de abril de 2004, no Teatro Shakespeare no Kennedy Center. Mais tarde, Nicholas Moschovakis e David Roessel publicaram o texto em uma coletânea de peças em um ato do autor de Um bonde chamado desejo, intitulada Mister Paradise and Other OneAct Plays de Tennessee Williams (2005)². A análise que propomos aqui tem dois eixos de reflexão. $\mathrm{O}$ primeiro, na esteira de James Francis (2007) procura demonstrar a consciência de Williams sobre o camp e as sexualidades desviantes, apresentada mais abertamente aqui do que em qualquer das suas outras peças de um ato ou de duração completa:

Em relação à temática homossexual, (...) em "Gata em Teto de Zinco Quente”, "De Repente no Último Verão" e "Um bonde chamado Desejo", podemos acrescentar que a palavra homossexual não se materializa verbalmente. No entanto, a imagem da perversão é latente, à medida que as personagens ridicularizam os homossexuais, ou expõem a sua opinião depreciativa. Essa perversão é coletiva e nunca encarada pelas personagens de frente. Há quem reconheça inúmeros signos de uma certa estética gay na obra de Tennessee Williams. Blanche pode ser vista como uma, Sebastian, o poeta gay, como símbolo de uma classe média perversa e manipuladora, bem como as idas contínuas de Tom a cinemas (distração com os filmes, ou com os frequentadores do cinema?). (SILVA, 2005, p. 16)

O segundo eixo intenta discutir a tradução da expressão queen e suas implicações no casting da personagem Candy na cena contemporânea. Este ensaio baseia-se em perspectivas críticas queer e em saberes de desaprendizagem (THÜRLER, 2018), para enfatizar as formas como E Contar tristes histórias das mortes das bonecas encena a homossexualidade como um elemento estético da peça.

Para justificar a afirmação de que a homossexualidade é um elemento estético da peça, vamos nos debruçar sobre o que temos entendido pelo camp, enquanto estética, embora não seja uma tarefa fácil, já que campé

1 Segundo Toledo e Flores, "Tennessee Williams é considerado um dos quatro pilares da dramaturgia estadunidense no século XX, ao lado de Eugene O'Neill (1888-1953), cuja carreira se consagrou nos anos 1920, Arthur Miller (1915-2005), seu contemporâneo, tendo ambos alcançado sucesso em meados da década de 1940, e Edward Albee (1928-2016), que escreveu sua primeira peça em 1959, quando Williams e Miller já eram autores consagrados" (TOLEDO; FLORES, 2018, p.32).

2 No Brasil, a tradução foi feita pelo Grupo Tapa e publicada em 2011. 
um termo em inglês de difícil tradução, que pode funcionar como adjetivo ou substantivo. $\mathrm{O}$ dicionário Michaelis traz como significado do substantivo camp (no sentido aqui empregado) "paródia, imitação burlesca", e como significado do adjetivo, "afeminado, exagerado, afetado". Outros dicionários oferecem definições menos pejorativas. O Webster's define camp, grosso modo, como estilo e uma sensibilidade que denota a apreciação do extravagante, do dramático e do exagero de estilo, e fá-lo, embora não de forma exatamente irônica, sem pretensão de completa seriedade. É algo diferente de kitsch: quando chamamos algo de kitsch - um vaso de flores de plástico, por exemplo - colocamo-nos numa posição de inequívoca superioridade; reconhecemos o mau gosto e a falta de estilo do objeto e afastamo-nos dele dizendo que é kitsch, brega e, em última análise, feio. $\mathrm{O}$ camp não adota essa posição, porque a relação entre o sujeito e o objeto não é de desdém; ao contrário, é de reverência (PRADO, 2017, sp),

ainda assim, estudiosos, críticos culturais, artistas e praticantes do camp vêm tentando fazer exatamente isso desde que Christopher Isherwood (1904-1986) ofereceu aos leitores uma deliciosa, embora fugaz, descrição da "sensibilidade gay", em seu romance de 1953, The World in the Evening. Segundo Isherwood, é na sensibilidade camp que "expressamos aquilo que nos é essencialmente sério através do divertimento, do artificio e da elegância" (ISHERWOOD, 2012, p. 101). Num breve diálogo entre dois amigos gays, Stephen e Charles, Isherwood distingue dois tipos de camp, o low camp, que inclui "rapazolas delicados, com cabelos oxigenados, chapéus de plumas e boás, imitando Marlene Dietrich", e o high camp, por exemplo,

the whole emotional basis of the Ballet, for example, and of course Baroque art. You see, High Camp always has an underlying seriousness. You can't camp about something you don't take seriously. You're not making fun of it; you're making fun out of it. You're expressing what's basically serious to you in terms of fun and artifice and elegance. Baroque art is largely camp about religion. The Ballet is camp about love. (ISHERWOOD, 2012, p.100-101)

Essas passagens de Isherwood, dão a entender sobre a elasticidade que o camp tem oferecido ao longo dos tempos. Quando Susan Sontag $(1964)^{3}$ escreveu suas famosas Notas sobre o camp, em 1964, a "sensibilidade gay" já havia deflagrado em outros terrenos culturais com gosto suficiente para se tornar tanto visível quanto disponível para a apropriação da cultura heterossexual. Do ponto de vista de Sontag, o camp perdeu sua atitude especificamente gay e passou a significar uma apreciação geral por objetos do passado: o passé, o démodé e o obsolete.

Em Guilty Pleasures (1996), Pamela Robertson começa por introduzir o termo camp ao discurso feminista, definindo o termo como um adjetivo que remonta ao início do século XX e se refere às pessoas, gays e lésbicas, "viciadas em ações e gestos de ênfase exagerada" (ROBERTSON, 1996, p.3). Portanto, Robertson critica a abordagem de Sontag ao camp, pois Sontag não mencionaria qualquer inter-relação entre este e o lesbianismo, que esteve, de fato, muito interligado à cultura dos homens brancos gays, até porque "o desafio das feministas ao patriarcado, à rigidez dos papeis de gênero e aos costumes sexuais tradicionais desencadeou uma discussão na sociedade brasileira que convergiu com as questões levantadas pelo movimento gay" (GREEN, 2000, p.394) o que, portanto, fez com que o camp circulasse sem qualquer estranhamento tanto em comunidades drags, como em comunidades

3 Em "Notas sobre o camp", Susan Sontag (1964) explora a ligação do sujeito à sexualidade. Sontag compôs o seu texto em forma de nota para demonstrar a incapacidade do camp para se enquadrar num sistema estruturado ou categorizado, da mesma forma que a sexualidade não pode ser tão facilmente definida. Sontag estabelece a sua própria compreensão do camp detalhando as suas características em 58 pontos, mas nunca fornece uma definição concreta. 
de lésbicas butch-femme e, claro, na cultura gay masculina. Essa compreensão encontra coro nos atuais discursos feminista e queer, para quem o camp, que se apropria dos seus objetos como artifício, opõese veementemente a qualquer ontologia essencialista e, por essa razão, se prestaria, especialmente, às críticas sobre a performatividade. Judith Butler (2003), por exemplo, interpreta a estética do camp característico das drag queens como uma crítica performativa do gênero a fim de desconstruir e desestabilizar categorias de identidade, incluindo a de gay.

Para Robertson (1996), o discurso feminista encontraria significado político no camp por razões semelhantes à de Butler, quando argumenta que os ícones do camp (ela cita Madonna e Mae West) podem e devem usar a cultura pop como um instrumento político e crítico na desconstrução da masculinidade e da feminilidade. Através da identificação com estes ícones, as mulheres poderiam escapar aos limites das visões redutoras sobre a feminilidade (ROBERTSON, 1996, p.53).

Segundo Susan Sontag (1964) e Mark Booth (1983), o ponto de partida mais sólido para o surgimento do termo camp parece ter sido, curiosamente, o final do século XVII e início do século XVIII, quando Luís XIV, o rei de França, fez despertar o extraordinário sentimento de artificialidade, de superficialidade e de ostentação. Booth afirma, também, que a palavra em si deriva do francês se camper que está relacionado com uma forma exótica exagerada e artificial de autoapresentação (BOOTH, 1983). Em discurso mais recente, diz-se que o gosto do camp é "[valorizar] o artifício sobre a natureza, o estilo sobre conteúdo, e [como resposta], pessoas e objetos com teatralidade e humor [...]” (MCELROY, 2014, p. 293).

Sontag, em seu texto, particularmente importante para a cultura gay, ainda adverte contra definições rígidas que ameaçam congelar a fluidez essencial da sensibilidade gay, a inefabilidade e a flexibilidade em algo mais difícil e nos adverte, "falar sobre o camp é traí-lo" (idem, p.105), talvez, por isso, ao longo de sua história, o camp tem se recusado a ficar parado.

Neste ensaio, no entanto, não vamos tentar definir o camp per se. Em vez disso, vamos intuir o camp através de exemplos, corporizado em personagens e lugares, objetos e artefatos a fim de esboçar alguns parâmetros da sensibilidade gay, olhando para a história de Candy, personagem central da peça de Tennessee Williams e percebendo que o camp, embora não fosse assim denominado, já era uma forma poderosa de visibilidade e de resistência queer, afinal, é a própria Candy quem prefere o "ornamento" (WILLIAMS, 2011, p.274) e a frescura para celebrar a "sociedade bichal" e, ao contrário de outras obras de Williams que apresentam retratos menos evidentes da homossexualidade, como apontamos ao citar Silva (2005), em E Contar Histórias Tristes..., o camp é retratado de forma explícita.

Nesse sentido, discordamos de Sontag quando associa o camp ao desengajado, ao despolitizado ou apolítico, perdendo a oportunidade de associar o camp ao queerness, a estratégias políticas de discussão sobre o "cistema” ou a qualquer projeto político de desaprendizagem (THÜRLER, 2018). Se Sontag restringe a potência camp apenas a uma questão de estética ou sensibilidade, em nossa opinião, a estética é política e, portanto, o camp é inerentemente político, produzindo em gays uma maior consciência das discrepâncias que existem numa sociedade heterocentrada e homofóbica, uma estratégia de sobrevivência para obter reconhecimento dentro dos espaços hetero-patriarcais. Nesse sentido, para além de uma sensibilidade gay, não se trata apenas de associá-lo a categorizações, low camp ou high camp, porque, de forma mais sucinta, não há diferentes tipos de camp, existe apenas um e ele é queer (MEYER, 1994). 
Durante a maior parte do século XX, enquanto "a homossexualidade era ainda tratada oficialmente pela medicina como 'desvio de transtorno mental'” (MACRAE, 2018, p.28) e era ilegal em todo o país (GREEN, 2000; MACRAE, 2018; PARKER, 2002), a vergonha, a ansiedade e o medo sustentavam a heterossexualidade compulsória. As rusgas da polícia a bares e casas de espetáculos de gays representavam uma ameaça à saída pública, à perda de emprego e à violência e, talvez, essa seja uma razão pela qual o camp e a homossexualidade têm estado intimamente ligados, porque são tipicamente considerados códigos fechados que devem ser ultrapassados para revelar as suas existências.

Nas palavras de Macrae, "os sentimentos de culpa e pecado que oprimem o homossexual são constantemente repostos por fatores sociais que o levaram a se ocultar, a ter medo do ridículo, da prisão, do desemprego, do ostracismo por causa de amigos e familiares” (MACRAE, 2018, p. 57). As comunidades gays existiam apenas à margem da cultura mainstream heterossexual e para fugir à detecção e à agressão, cultivaram códigos sociais particulares, gestus sociais complexos, marcadores linguísticos para sobreviver ${ }^{4}$. Quando nos referimos ao gestus, queremos importar de Brecht a ideia de diferenciação entre este e a simples gestualidade, porque "nem todos os gestos são sociais. A atitude de espantar uma mosca não é um gesto social [...]. O gesto de trabalhar é definitivamente social, porque toda atividade humana dirigida para a dominação da natureza é um empreendimento social, e um empreendimento entre homens" (BRECHT, 2005, p. 104). Assim, se para Brecht, gestus se refere àqueles gestos que se articulam com a rede de conexões sociais para sustentar suas relações, queremos dizer que nas comunidades gays, o gestus era o camp, que

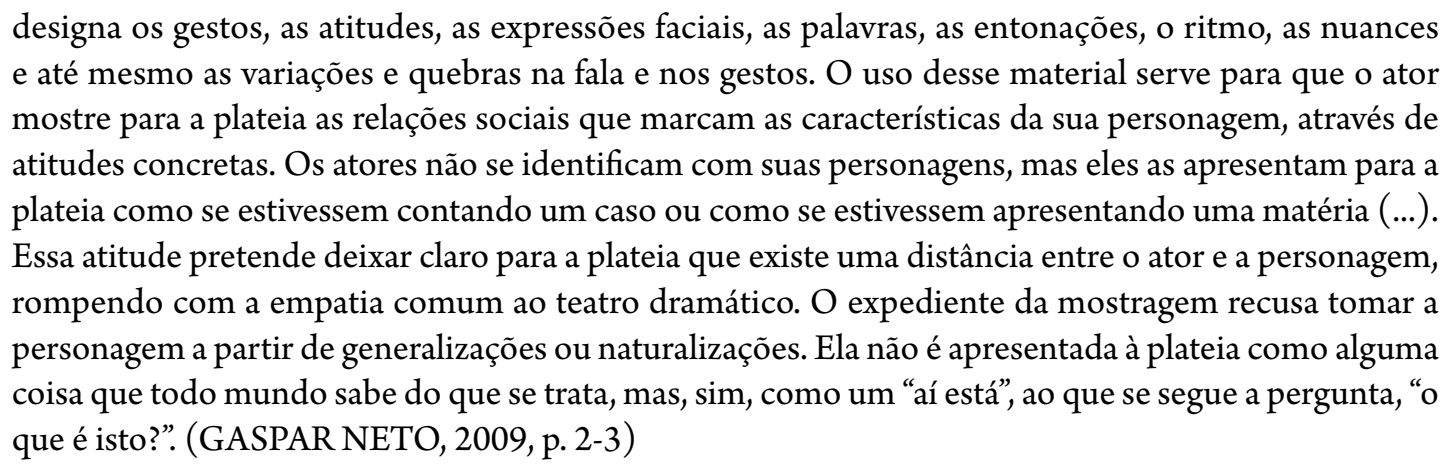

Assim, dois mundos sociais viraram-se, um dentro do outro, permitindo que indivíduos homossexuais se misturassem superficialmente com a multidão. Por exemplo, uma rua ou parque da cidade pode parecer apenas um espaço público, mas para qualquer pessoa com um conhecimento privilegiado, um olhar ou um toque, uma cor particular, uma expressão pajubá ou uma inflexão vocal, podem abrir a porta do armário apenas o suficiente para dar uma espreitadela no fabuloso outro mundo, uma certa incongruência entre a necessidade de esconder algo e de revelá-lo ao mesmo tempo. Nesse sentido, a aproximação do camp ao gestus brechtiniano não se faz sem sentido, se trata abertamente da afirmação da identidade bicha da época enquanto afirmação política e isso implicava, necessariamente, a existência de um fosso, de uma diferença entre a vida real e a "sociedade bichal", entre a ação cotidiana e a ação teatralizada, o que torna o camp a metáfora da vida como um teatro.

4 Sobre este assunto, sugerimos a leitura de "Os efeitos marginalizadores da heteronormatividade em The boys in the band, de Djalma Thürler e Duda Woyda. 
Aliás, a palavra bicha demorou muito tempo a tornar-se comum no Brasil, que durante muito tempo preferiu a identificação homossexual, que persistiu durante os primeiros três quartos do século XX, “matizada por diferentes termos como 'viado, 'bofe', 'ativo', 'passivo', 'gay', 'entendido' etc.” (MACRAE, 2018, p.27), aliás, mesmo processo que a tradução da palavra queer - nesse caso por uma "intraduzibilidade epistemológica" (JIMENEZ, 2002, p. 19) -, ao ser utilizada como "xingamento voltado aos homossexuais e a toda sorte de 'desviante' sexual, de sujeito fora dos padrões de comportamento, podendo ser precariamente vertida para o português como bicha, veado ('viado'), boiola, puto, boneca”. E, exatamente para combater o estigma semântico, suas conotações negativas, que se adotou, como postura política, ressignificar o termo 'bicha' (MACRAE, 2018). Assim, a palavra 'bicha' deixa de ser uma designação discriminatória, abjeta e passa a ser uma questão de identidade construída em torno de práticas que respondiam tanto a gostos particulares (em relação a uma maioria) como comuns (em relação a si próprias), tornando-se popular entre nós nos anos de 1980, mas perceptível, também, em E Conta Histórias Tristes..., que fora escrito quase 30 anos antes, em 1957. Reparem quando Candy responde a Karl sobre se seus inquilinos seriam "garotas":

CANDY: Mulheres? Ah não, nunca mais alugo para mulheres na minha vida. Além de atrasarem o pagamento, são desmazeladas e destrutivas. Não. Esses inquilinos são dois rapazes do Alabama: bonecas jovens, claro. Nem pensar em alugar para outro tipo de gente. Bonecas são inquilinos maravilhosos, cuidam muito bem do lugar. Às vezes fazem até melhorias. São muito caprichosas e prendadas. Elas estabelecem o estilo e ditam moda no país. Você não sabe disso? (WILLIAMS, 2011, p. 271. Grifo nosso.)

Na continuidade da cena, Candy adverte Karl:

CANDY: Imagina este país sem bonecas. Seria uma completa barbárie. Olha esses lares de casais normais. Nenhuma originalidade: misturam moderno com antigo, tudo amontoado em volta de uma enorme TV na sala de visitas. Têm paixão pela mediocridade. Conformados. Convencionais. Mas eu também sei dos defeitos das bonecas, ninguém conhece os defeitos das bonecas melhor do que eu.

KARL: Bonecas?

CANDY: O quê?

KARL: Você é veado?

CANDY: Meu amor, você está brincando?!

KARL: Dá pra responder a pergunta?

CANDY: Ah, não, é sério?

KARL: Hã? (idem).

O que se poderia notar do excerto acima é que, ao referir-se aos seus inquilinos como bonecas, Williams está, não apenas associando-os a uma identidade desviante, mas, também, a uma sensibilidade camp de identificação e de pertencimento que, aliás, raramente tem sido explorada em relação ao teatro, sobretudo em produções que escapam aos estereótipos habituais e aviltantes sobre as sexualidades desviantes, ignorando as associações complexas do termo. Pela ótica de Rodrigo Dourado, o termo desviante é utilizado "para falar dessas identidades fora do padrão, ou seja, de sujeitos que são marginalizados e excluídos por 'destoarem', se 'desviarem' da norma heterossexual e cis" (apud MASCARENHAS, 2018, sp). E esse, sem dúvidas, é o caso de Candy. 
Por isso, daqui em diante, nos debruçaremos sobre o segundo eixo do artigo, o de pensar sobre a tradução do substantivo queens/bonecas na edição brasileira e os desdobramentos que essa tradução pode ter na escalação do elenco, em especial, da protagonista Candy. Para Luis Marcio Arnaut (2018), que analisa a peça Not about Nightingales, também de Williams e que tem uma personagem chamada Queen, "aos olhos contemporâneos, a personagem pode ser compreendida como uma travesti por conta da sua caracterização” (ARNAUT, 2018, p. 33).

Em uma mesa redonda durante o Festival MinhoQueens de Cultura Drag, Rita Von Hunty afirma que

as nossas drags não aparecem no planeta chamadas drag queens, esse já é [resultado do] movimento de luta e de cultura. O termo queen, nos Estados Unidos, designa algo como bicha, baitola, viadinho. Então, o Tennessee Williams, que é um dos maiores autores de teatro norte-americano tem uma peça chamada And Tell Sad Stories of the Deaths of Queens, ou Contar tristes histórias das mortes das bonecas. Essa peça, ela se baseia na história de Candy, personagem central que, na época, a sociedade ainda não tinha a capacidade de distinguir a travesti da drag queen, então, ela é essa figura híbrida entre a drag queen e a travesti. Essa peça é dos anos 30 (sic) e, basicamente, conta a jornada, a vivência e os conflitos de classe, os interesses dessa personagem central e, na História, é uma das primeiras vezes que uma personagem central será uma trans, ou como se chamava na época, transviada. (HUNTY, 2021, $29 \mathrm{~min}$ )

Não ter a capacidade de distinguir a travesti da drag queen dá uma boa medida da complexidade que é a performance de gênero de Candy, mas, também, reforça a ideia da definição do texto teatral como "uma máquina preguiçosa que exige do leitor um renhido trabalho cooperativo" (ECO, 1986, p. 11). De nossa parte, enquanto leitores, no esforço para que "uma verdadeira cooperação emerja" (RYNGAERT, 1998, p. 3), destacamos a didascália inicial do texto, que descreve Candy como

uma boneca de Nova Orleans, perto dos seus 35 anos, um tipo de semblante que nunca parecerá adulto e uma graça e esbelteza que sempre vão sugerir um jovem efeminado. A feminilidade de Candy é natural demais para precisar ser expressada por meio de trejeitos ou de voz: o papel deve ser representado sem caricaturas. (WILLIAMS, 2011, p. 267-268. Grifo nosso.)

Ao que parece, nessa introdução, Williams quer comunicar, a partir da descrição de Candy, que se trata de um personagem masculino delicado, uma bicha pós-balzaquiana que performa uma feminilidade extremamente natural. Natural, no sentido aplicado pelo autor, quer dizer verossímil, que para a dramaturgia clássica "é aquilo que nas ações, personagens, representações, parece verdadeiro para o público, tanto no plano das ações como na maneira de representá-las no palco" (PAVIS, 1999, p. 428. Grifo do autor), por isso, representar Candy de forma caricata seria um atentado contra a verossimilhança e, portanto, contra a estética que privilegia a verossimilhança na interpretação já que, conforme Pavis, “a verossimilhança é um conceito que está ligado à recepção do espectador” (idem).

Quando Candy vai em direção ao que parece ser o seu quarto ("Candy atravessa a cortina de bambu indo para a área onde está a cama” (WILIAMS, 2014, p. 276) mantém, à distância, diálogo com Karl, de onde podemos extrair elementos textuais que colaboram para alguma identificação sobre seu gênero: "quando eu era uma franguinha, uma galinha tonta, eu sabia que havia algo de errado comigo, mas não que eu era bicha. Ele [Mr. Sidney Korngold - depois, seu marido] achou que eu era uma menina vestida de menino. Eu disse que era menino, indignado" (idem). Neste excerto, notamos que a indignação de Candy com a ambuiguidade de gênero que sua performance provocara, demonstra, dentro do debate atual sobre as categorias sexuais, que ela era reconhecida socialmente como um 
homem homossexual cisgênero andrógino e essa ligação do camp à sexualidade andrógina, na esteira de Sontag (1964), colabora para libertar o termo de definições mais restritas. Maffesoli observa "cada vez mais, [há] um vaivém constante entre as qualidades ditas femininas e as que eram o apanágio do homem viril. É isso que determina uma personalidade de base andrógina, onde os contrários misturamse em esponsais dos mais fecundos (MAFFESOLI, 1996, p. 320).

Se a personagem é definida pelo que ela fala de si e pelo que dela falam (a essa altura, já sabemos que Candy é um decorador de interiores e proprietário de imóveis no bairro francês de Nova Orleans e que aluga duas outras propriedades e o andar de cima da sua casa a garotos gays extrovertidos), ela mesma começa a tornar mais complexa sua identidade. Ainda durante a cena anterior, diante de sua demora no quarto, Karl pergunta

KARL: O que você está fazendo aí?

CANDY: Trocando de roupa. E de sexo. (Ele surge como uma drag). Eu sou um travesti. Aqui estou.

KARL: Você é louco

CANDY: Não, só muito anormal. Eu acho.

KARL: Bom, tenho que admitir...

CANDY: O quê?

KARL: Você é tão mulher como qualquer uma que eu já vi.

CANDY: Obrigada essa é a intenção.

KARL: Tem certeza de que você não é mulher?

CANDY: Quer que eu mostre?

KARL: Não.

\section{(...)}

CANDY: Você vai notar que agora estou sendo muito feminina, tanto no meu jeito de falar e nos meus maneirismos, quanto na minha aparência. Não é isso que você quer?

KARL: Você faz isso sempre?

CANDY: Sempre que estou sozinha. É geralmente quando estou sozinha, quando chego à noite, eu coloco o meu cabelo e entro num négligé limpinho. Tenho dez, de todas as cores do arco-íris, alguns valem uma pequena fortuna. Ha ha, não uma pequena fortuna, digo cem ou duzentos... (WILLIAMS, 2011, p.277-278).

Várias passagens desse diálogo, tenso e bem-humorado, ajudam a compreender mais camadas da identidade de gênero de Candy. Notem sua prática de montação ${ }^{5}$, do tornar-se mulher a partir do travestismo (female impersonators), comum, também, no Brasil durante algumas atividades recreativas, como o carnaval e alguns encontros pessoais; e profissionais, como o teatro de Revista da primeira e segunda ondas 6 . Quando revela, depois de surgir como uma drag, "eu sou um travesti", Candy esconde

5 "Se montar" é como as drag queens comumente denominam o processo de transformação da sua aparência, que pode ser feita com a utilização de figurinos específicos, maquiagem, próteses e acessórios. Há, também, mudanças na entonação, na presença e no comportamento.

6 Thürler e Bia Mathieu, em texto ainda inédito, afirmam que as presenças nos palcos brasileiros das artistas transformistas Aymond, entre os anos 1920 e 1930, e de Ivaná, entre 1950 e 1960, delimitam a primeira onda da cena travesti, tendo como características fundamentais, a imitação de mulheres e o legado estético e discursivo do Teatro de Revista, que antecederia a explosão desses espetáculos, a partir de 1960. Afirmam ainda que o boom da cena travesti, que corresponde à segunda onda, remonta às produções dos anos 1960 a 1980 até a chegada da AIDS, corresponde, concomitante, à explosão da homossexualidade no país e a consequente expansão da "sociedade bichal". 
a sua masculinidade num esforço para atrair Karl, mas, também, se vangloria da facilidade desta transformação lembrando, simultaneamente a Karl, que há um homem por baixo da sua maquiagem e do seu figurino. Essa performance insinua que o travestismo era uma prática recorrente em sua vida ([Faço isso] "sempre que estou sozinha"). Vale lembrar que

$$
\begin{aligned}
& \text { nas décadas iniciais do século XX, reuniões e festas entre gays eram promovidas em segredo, nas casas dos } \\
& \text { homens ou até mesmo dentro de cinemas, em que aconteciam desfiles de misses e nos quais os amigos } \\
& \text { se tratavam usando nomes no feminino - apesar disso, os frequentadores e participantes dos "concursos" } \\
& \text { não adotavam trajes do outro gênero, apenas roupas mais requintadas e maquiagem discreta. O carnaval } \\
& \text { era a única ocasião em que podiam usar roupas femininas em público, por se tratar de uma celebração } \\
& \text { que sempre esteve associada ao uso de fantasias e à prática do cross-dressing. (OLIVEIRA, 2017, p.15) }
\end{aligned}
$$

No Brasil, por exemplo, temos o caso da Turma OK, fundada em 13/01/1961, cuja história foi recentemente lembrada por duas de suas principais testemunhas, Elaine Parker (César Amâncio, atual presidente da TURMA OK) e Lady Benedita de Orleans e Bragança Bourbon e Bourbon (conhecido por Soca, o frequentador mais antigo vivo), em entrevista a Rodrigo Faour, no programa Arquivos da cena LGBTQI+ carioca.

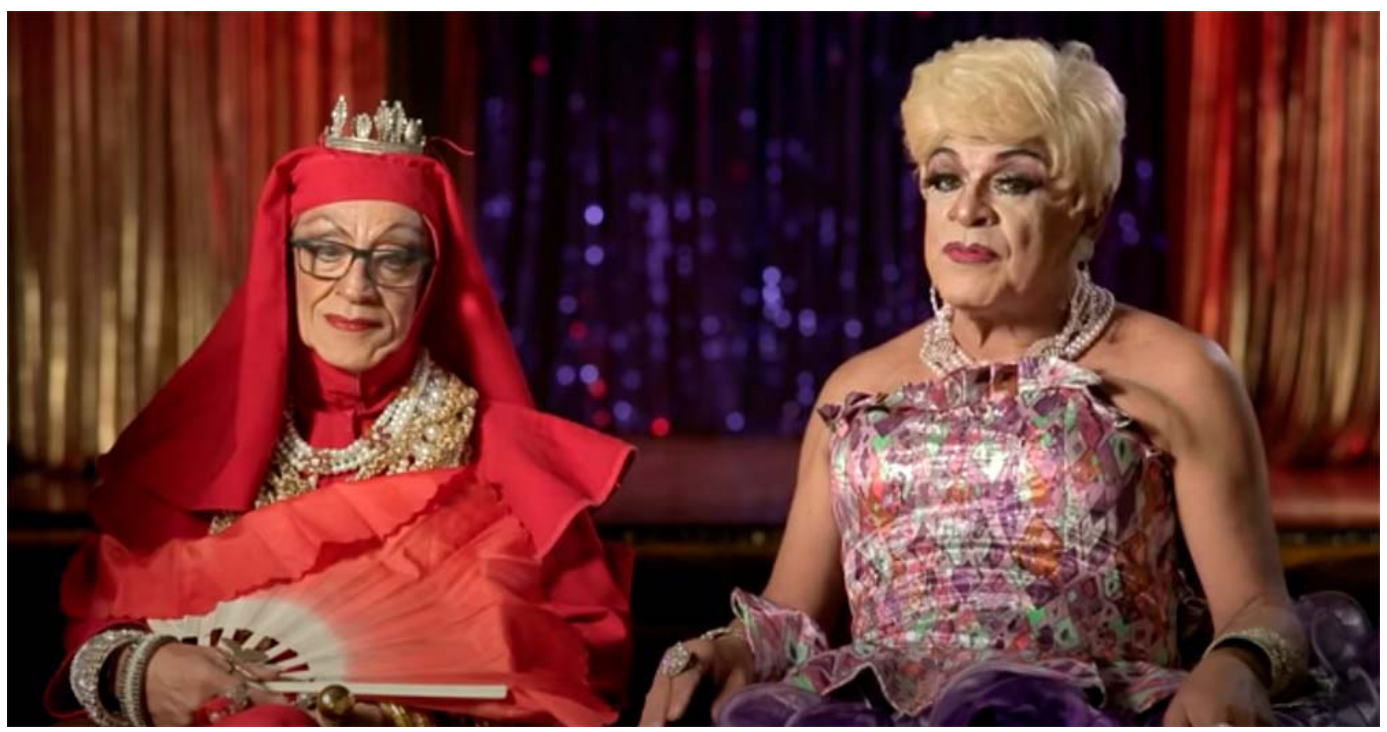

Figura 1 - Lady Benedita/Soca e Elaine Parker/César Amâncio. Reprodução do Canal de Rodrigo Faour.

Thiago Barcelos Soliva, em A confraria gay: um estudo sobre a trajetória da Turma OK (2018) relata que este espaço "congrega um conjunto variado de atividades que incluem festas, reuniões, concursos e, principalmente, 'shows de artistas transformistas', itens emblemáticos desse grupo" (SOLIVA, 2018, p. 122). Soliva, agora em outro texto, afirma que nas décadas de 1950 a 1970, a noção de "bicha" abarcava, simultaneamente, o que hoje definimos por "homossexuais" e "travestis", afinal, “'Homossexuais', 'travestis', 'bissexuais', 'transexuais' e outras identidades coletivas e expressões de gênero são construções bem recentes no que é possível chamar de 'história das homossexualidades no Brasil', e mesmo em outras realidades" (2016, p. 25), por isso, conclui o autor, "falo de um universo povoado por 'bichas,' 'bofes,' 'frescos', 'homens em travesti', 'bonecas', 'enxutos,' 'travestis profissionais', 
etc. - categorias vinculadas às experiências sociais de indivíduos situadas por constrangimentos sociais e contextos históricos" (idem p. 28).

No caso de Candy, se sua "perfechatividade de gênero" 7 (COLLING; ARRUDA; NONATO, 2019) é inescapável, está talhada em seu próprio corpo como anunciada pela primeira didascália, seu hábito de se vestir de mulher, sua mulheridade construída - sempre dentro do armário aparece pela primeira vez nesta cena, de certa forma, demonstrando seu gosto pelos maneirismos de personalidade e pelas sexualidades permeáveis (SONTAG, 1964). Dessa forma, Candy se torna a principal chave de definição do camp à medida que concilia sua identidade desviante com sua evidente ubiquidade.

Ainda sobre esse excerto, vale destacar que o hábito de se montar sozinha pode ser revelador de, pelos menos duas outras características de Candy, a primeira é a de que ela estaria distante da politização e da espetacularização do fascínio sexual de sua ambiguidade (LEITE JR., 2008). A outra, faz referência à Epistemologia do Armário, de Eve Sedgwick, ao segredo aberto (2007), afinal, Candy está "fora" apenas quando revela o seu segredo para membros de uma audiência que ela escolhe, ao mesmo tempo em que se esconde de outros.

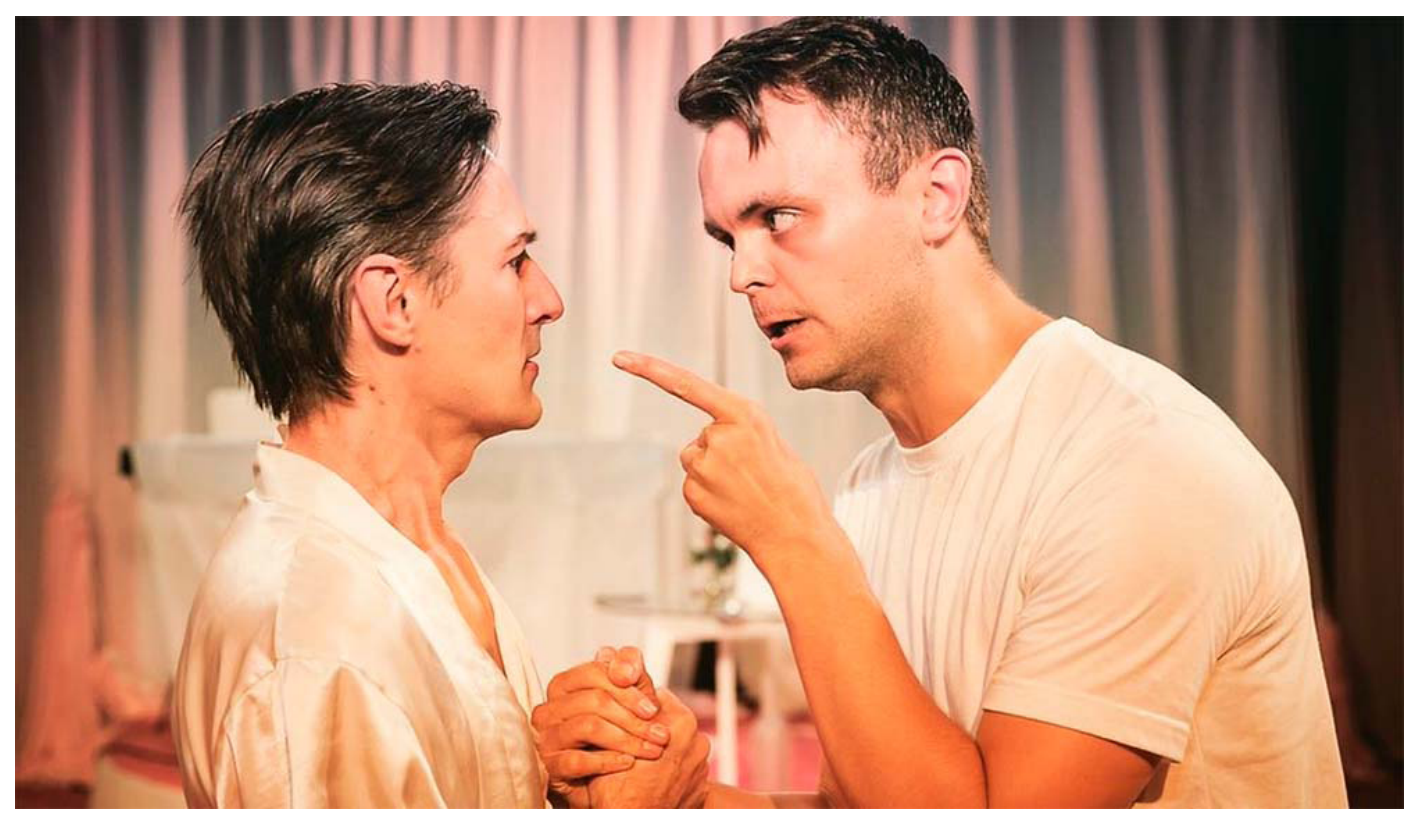

Figura 2 - Luke Mullins (Candy) e George Fletcher (Karl) em encenação de Jamie Armitage.

E Contar tristes histórias das mortes das bonecas é uma peça praticamente desconhecida e injustamente negligenciada sobre o desejo e a autoilusão de que exista um relacionamento real, já que Candy diz que está sozinha e só quer amizade, mas parece estar tentando enganar Karl, e talvez a si mesma. Candy falha na tentativa de fazer com que Karl a ame ${ }^{8}$. Toda a sua vida, a mentira de

\footnotetext{
7 Os autores sugerem pensar as "expressões de gênero de gays afeminados fechativos (ou das gays afeminadas fechativas) como perfechatividades de gênero, o que aglutinaria uma combinação entre fechação e performance, ainda naquele sentido de que por vezes é realizada de forma bem mais intencional, e performatividade, quando a intencionalidade diminui e a repetição torna-se mais naturalizada, mas que, no sentido antropológico de Cohen (2002), não deixa de ser também”. COLLING; ARRUDA; NONATO, 2019, p. 30).

8 O camp is a disguise that fails (CORE, 1994, p. 7).
} 
seus sonhos e memórias são destruídos pela dura verdade do seu envelhecimento e pela negação de Karl dos seus afetos ${ }^{9}$.

Mas não é uma obra menor dentro do universo dramatúrgico de Tennessee Williams. Escrita em 1957, como já dissemos, no auge da sua fama, nunca foi encenada durante sua vida e não foi publicada até muito depois de sua morte. O título deriva do discurso final de Richard II, de Shakespeare:

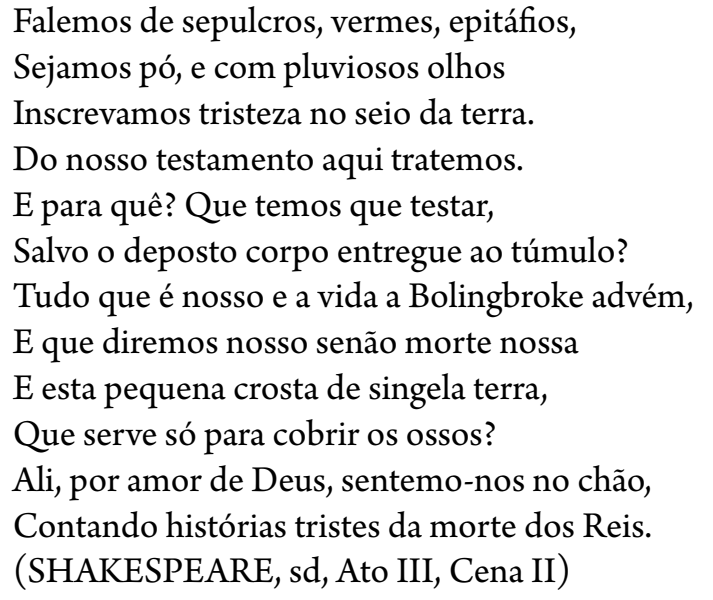

Acusado de criar personagens femininas de destaque que eram substituições de homens gays apresentar personagens gays era "irrepresentável em seu tempo" (BETTI, 2007, p. 152) -, com Candy, Williams cria através da estética camp sua vida como um teatro, uma mise-èn-scene ${ }^{\mathbf{1 0}}$ sobre a construção social do gênero, já que este pode ser entendido como uma atuação, uma espécie de personificação persistente que se equipara ao real, e explora a eficácia do camp como uma forma de resistência irônica, mas, ainda assim, uma poderosa crítica cultural para aquela subcultura, porque o seu uso constituía um ato de ir a público ou sair do armário, antes mesmo do surgimento da política de libertação gay, ou seja, em 1957, as sociedades já estavam em movimento sobre o que deveria ser masculino e o que deveria ser feminino. Karl, que não é gay, não quer admitir que gosta da companhia de outro homem, mas se encontra frequentemente em situações comprometedoras com eles, deleitando-se em ganhar dinheiro ao assegurar alguns favores sexuais às bonecas, como quando diz a Candy: "Tudo isso faz parte de um plano. De você eu só quero um pouco de dinheiro. Pode fazer o que quiser, mas por dez dólares. Vamos acabar logo com isso? (WILLIAMS, 2004, p. 283. Grifo nosso).

Por fim, essa complexidade sobre a performance de gênero de Candy é que, ao nosso ver, gerou tantas e diferentes interpretações pelo mundo, como a de Rob Tucker, na encenação da EgoPo Classic Theater ${ }^{11}$ e a de Luke Mullins, em 2018, só para citar duas das inúmeras Candys que têm sido encenadas pelo mundo, inclusive no Brasil. $O$ fato é que a personagem Candy Delaney requer um ator que tenha, paradoxalmente, a vulnerabilidade e a força exigidas das personagens femininas de Williams, mas que também faça a transição suave entre o homem que vemos trazer Karl para casa, antes que ele reapareça como Candy. O fato de Candy, interpretada por Rob Tucker, ser um ator negro - o que faz todo o

9 O camp is a lie which tells the truth (CORE, 1994, p. 7).

10 O camp is an art without artists (CORE, 1994, p. 7).

11 Vejam a entrevista de Tucker a Roger Walker-Dack em https://fb.watch/577fdLT94T/, em que aparece algumas cenas de peça em que o primeiro interpreta Candy. 
sentido para um cenário de Nova Orleans -, também acrescenta camadas interseccionais à violência e à vulnerabilidade que Candy enfrenta na peça, o que cria uma representação mais diversificada da comunidade queer que Williams propõe nesta peça. Nas figuras 3 e 4, se aprsentam as diferentes versões de Candy, a primeira pelo ator Rob Tucker; a segunda por Luke Mullins.

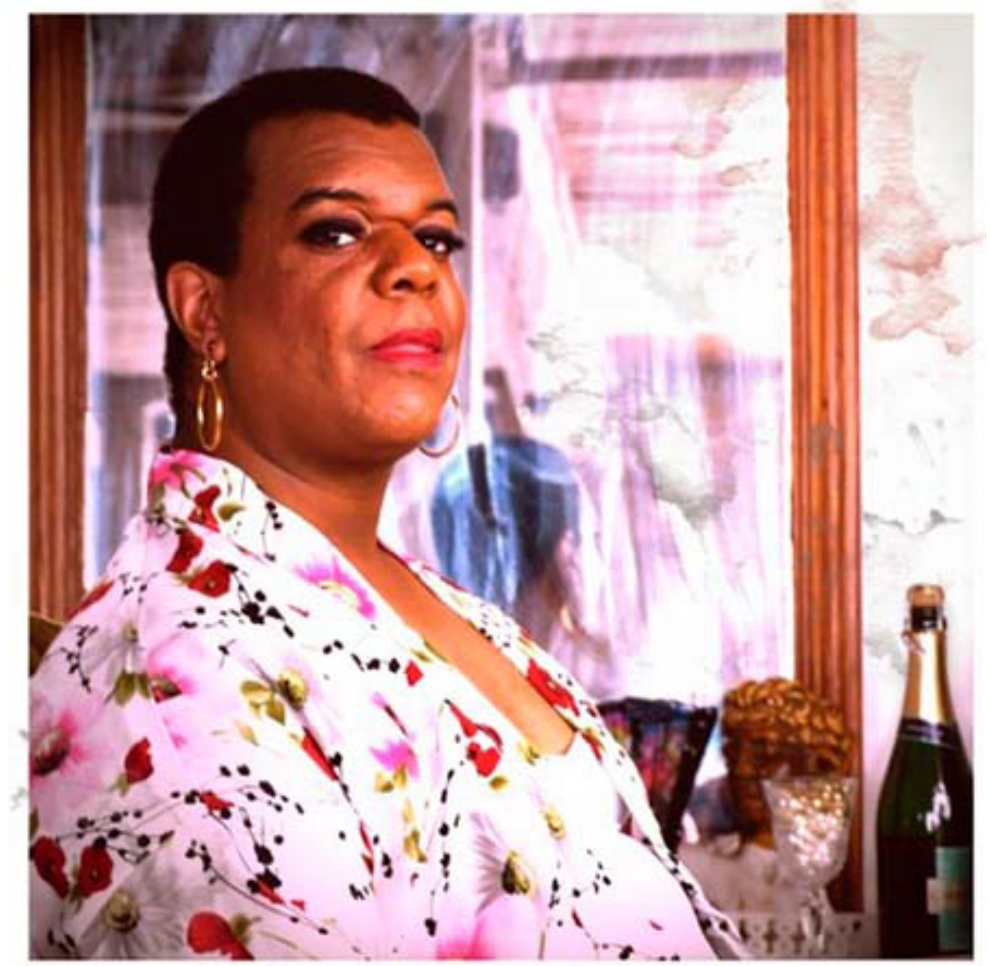

Figura 3 - Rob Tucker, em montagem de 2019, dirigida por Lane Savadove, em Filadélfia.

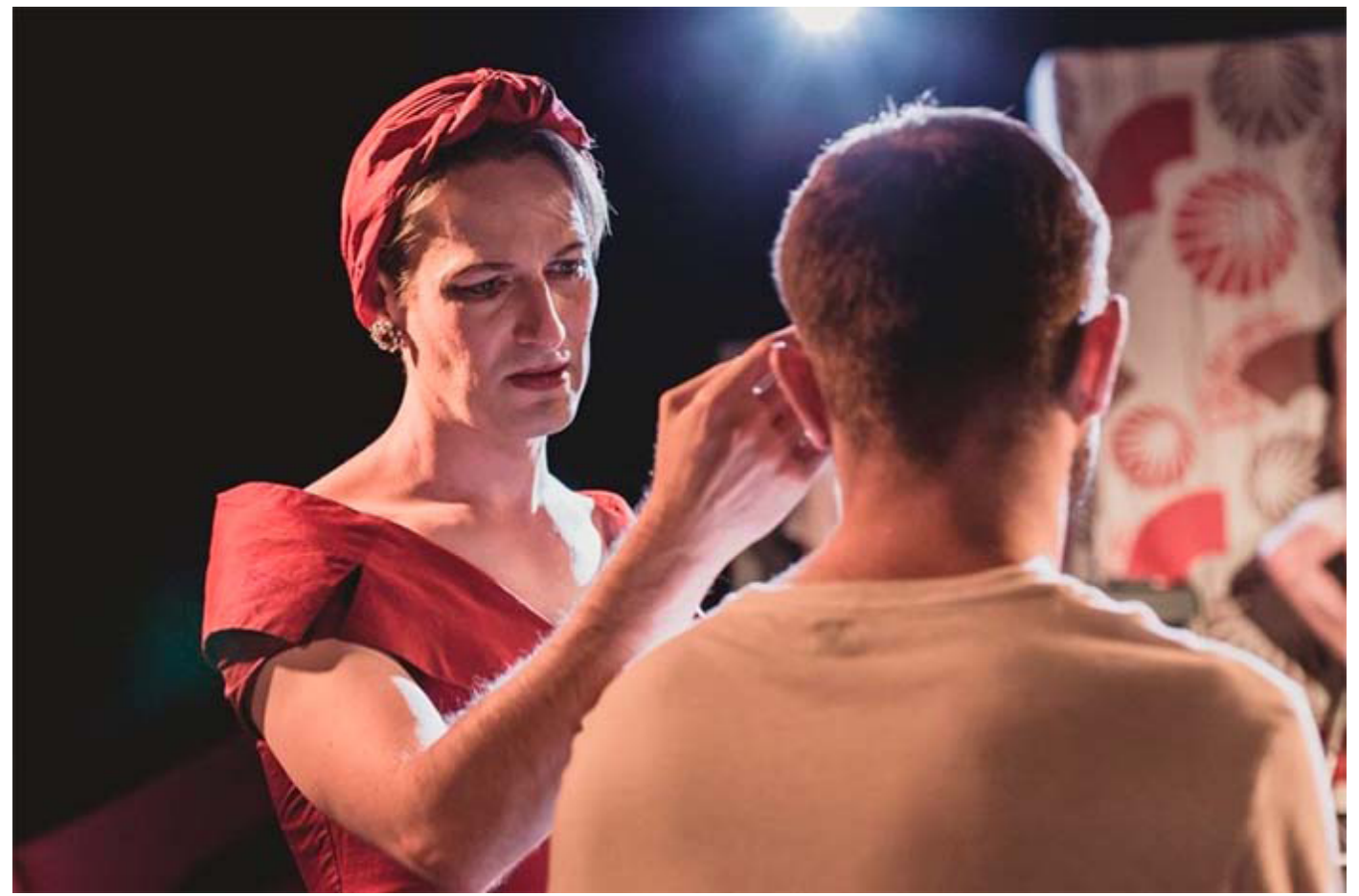

Figura 4 - Luke Mullins, em montagem de 2018, dirigida por Jamie Armitage, em Londres. 
Embora Candy pareça autoconfiante no início da peça, gradualmente revela uma grande autoaversão ("O mundo das bonecas é excitante só para as bonecas jovens. Pra mim, é passé e finit" [WILLIAMS, 2011, p. 292]), tema que enfrenta uma polêmica na comunidade LGBT; de modo geral, qual o tipo de histórias que deveríamos estar a contar sobre nós mesmos? Por que é que tantas narrativas homossexuais acabam em tragédia? Por que dar voz a uma peça em que o protagonista bicha é repetidamente menosprezado e agredido pela sua identidade de gênero e expressão sexual? Por extensão, haveria algo intrinsecamente trágico sobre a condição de ser homossexual?

É certo que, no passado, contávamos histórias tristes porque esta era a única narrativa que a cultura cissexista ${ }^{12}$ podia suportar: um mundo onde as personagens não normativas ou estavam tristes ou mortas no final e a peça de Williams cai mesmo no âmago deste argumento. Mas contra isso não só os finais felizes parecem ser a única opção sociopolítica viável. A jornada da heroína de Candy ensina - a dor é pedagógica - que o mundo de "matriz branca heterocisnormativa binariocêntrica reprodutivista" (NASCIMENTO, 2019, p. 11) impõe a todo momento a sensação de sermos dispensáveis ou de sermos descartados (BUTLER, 2008, p. 21), nos conduzindo, no terreno do afeto, quase sempre, a um jogo amoroso predatório, a experiências radicais de solidão, a traumas psicológicos profundos e comportamentos autodestrutivos a fim de forçar uma espécie de felicidade para nós mesmos, custe o que custar; mas, também, oferece ao público, através de sua performance genderfuck (BRIGHT, 1999 apud REICH, 1993), novas maneiras de viabilização do cotidiano numa clara recusa às políticas identitárias, a partir de sua subjetividade flexível (ROLNIK, 2008).

Candy-historiadora nos convida a recordar o passado e honrar aquelas que lutaram as batalhas, que empurraram a comunidade LGBT para o seu estatuto atual, mas, também, nos lembra que ainda há trabalho a ser feito para assegurar que o progresso continue. Candy-filósofa é plenamente conhecedora da influência e fascínio da cultura camp para a América cisheterossexual, afinal, um país sem bonecas, "seria uma completa barbárie" (WILLIAMS, 2011, p. 271) diz ela e, afirma, a partir de sua própria encenação, que caberia às estruturas culturais a produção de uma outra política de subjetivação para desprogramar a heteronorma e acomodar todos os tipos diferentes de narrativas que pudessem confrontar os imperativos culturais sobre os gêneros masculino e feminino, que, sabemos, não são naturais ou essenciais, concluindo de forma oportuna e reveladora com um importante momento de solidariedade ao lado de seus inquilinos, Jerry e Alvin, que deixa o público com um sentido de esperança para levar para casa, afinal, embora esta seja uma história triste, não é, finalmente, uma tragédia.

12 “Sociedade tão cissexista que sequer conseguisse enxergar o próprio cissexismo" (RODOVALHO, 2017, p. 365-366). 


\section{REFERÊNCIAS}

ARNAUT, L. M. “Tennessee Williams não parece ele mesmo: expressionismo e crítica social em Not About Nightingales." Revista Moringa - Artes do Espetáculo, v. 9, n. 2, 2018, p. 27-36.

BETTI, M. S. "Alegoria Política e Representação em Camino Real, de Tennessee Williams”. In: CHAIA, M. (org.) Arte e Política. São Paulo, Programa de EstudosPós-graduados em Ciências, 2007.

BOOTH, M. Camp. London: Quartet, 1983.

BRECHT, B. Estudos sobre Teatro. Rio de Janeiro, Nova Fronteira, 2005.

BUTLER, J. Problemas de gênero: feminismo e subversão da identidade. Rio de Janeiro: Civilização Brasileira, 2003.

BUTLER, J. Corpos em aliança e as políticas das ruas: notas para uma teoria performativa em assembleia. Trad. Fernanda Siqueira Miguens. Rio de Janeiro: Civilização Brasileira, 2008.

COLLING, L.; ARRUDA, M. S.; NONATO, M. N. "Perfechatividades de gênero: a contribuição das fechativas e afeminadas à teoria da performatividade de gênero." Cadernos PAGU, n. 57, Campinas, 2019, p. 1-34. Disponível em: https://periodicos.sbu.unicamp.br/ojs/index.php/cadpagu/article/view/8658138

CORE, P. Camp: The Lie That Tells The Truth. London: Plexus Publishing (UK), 1994.

ECO, U. Lector in fábula. São Paulo: Perspectiva, 1986.

FAOUR, R. Arquivos da cena LGBTQI+ carioca. In: Youtube: https://www.youtube.com/ watch?v=xGLIEItYhRY\&t=132s, 07 de abr de 2021. Acesso em $08 \mathrm{~d}$ abr de 2021.

GASPAR NETO, F. de A. "O gesto entre dois universos: a noção de gestus no teatro de Bertolt Brecht e no cinema dos corpos de Giles Deleuze." Revista Científica/FAP, Curitiba, v.4, n.1 p.1-15, jan./jun. 2009. Disponível em: http://periodicos.unespar.edu.br/index.php/revistacientifica/article/view/1594

FRANCIS, J. "Camping Out: Sexuality as Aesthetic Value in Tennessee Williams's And Tell Sad Stories of the Deaths of Queens." The Tennessee Williams Annual Review, Issue 9, 2007, p. 1-9. Disponível em: https:// tennesseewilliamsstudies.org/journal/work.php?ID=85

GREEN, J. Além do carnaval: a homossexualidade masculina no Brasil do século XX. São Paulo: UNESP, 2000.

HUNTY, R. V. Festival MinhoQueens de Cultura Drag - Live 5. In: Youtube: https://www.youtube.com/ watch?v=dmpMztqy6og\&t=2034s, 11 de mar de 2021. Acesso em 11 de abr de 2021.

ISHERWOOD, C. The world in the evening. Coleção: Vintage Classics, 2012.

JIMENEZ, R. M. Sexualidades transgresoras: una antología de estudios queer. Barcelona: Icaria, 2002.

LEITE JR., J. Nossos corpos também mudam: sexo, gênero e a invenção das categorias "travesti” e "transexual” no discurso médico científico. Tese (Doutorado em Ciências Sociais) - Pontifícia Universidade Católica, São Paulo, 2008.

MACRAE, E. A construção da igualdade: política e identidade homossexual no Brasil da abertura. Salvador: EDUFBA, 2018.

MAFFESOLI, M. No fundo das aparências. Trad. Bertha Halpern Gurovitz. Petrópolis: Vozes, 1996.

MASCARENHAS, P. Bonecas falando para o mundo. Continente, 25 jul 2018. Disponível em: https:// revistacontinente.com.br/secoes/curtas/bonecas-falando-para-o-mundo. Acesso em: 12 abr. 2021.

MCELROY, D. Camp. Macmillan Interdisciplinary Handbook Series, 2014, p. 293-309.

MEYER, Moe. The Politics and Poetics of Camp. New York, Routledge, 1994.

NASCIMENTO, T. Cuírlombismo Literário. São Paulo: n-1 edições, 2019. 
OLIVEIRA, F. N. "Gênero, cultura e o dispositivo da transexualidade: A formação da identidade travesti no Brasil.” Darandina Revisteletrônica, Programa de Pós-Graduação em Letras/ UFJF, volume 10, número 1, 2017, p. 1-20. Disponível em: https://periodicos.ufff.br/index.php/darandina/article/view/28254

PAVIS, P. Dicionário de Teatro. Trad. J. Guinsburg; Maria Lúcia Pereira. São Paulo: Perpectiva, 1999.

PARKER, R. Abaixo do Equador: cultura do desejo, homossexualidade masculina e comunidade gay no Brasil. Trad. Ryta Vinagre. São Paulo: Record, 2002.

PRADO, A. “Como ser gay, o novo livro de David Halperin.” Revista CULT, 2017. Disponível em: https:// revistacult.uol.com.br/home/como-ser-gay-uma-resenha/. Acesso em: 14 jun. 2020.

REICH,J. L. “Genderfuck: The Law of the Dildo." Discourse: Journal for Theoretical Studies in Media and Culture. Vol. 15 : Iss. 1 , Article 7, 1993, p. 112-127. Disponível em: https://www.jstor.org/stable/41389251?seq=1.

ROBERTSON, P. Guilty Pleasures: Feminist Camp from Mae West to Madonna. Durham and London: Duky University Press, 1996.

RODOVAlHO, A. M. “O cis pelo trans.” Rev. Estud. Fem. vol.25 n.1, Florianópolis, 2017, p. 365-373. Disponível em: https://www.scielo.br/pdf/ref/v25n1/pt_1806-9584-ref-25-01-00365.pdf.

ROLNIK, S. “Geopolítica da cafetinagem.” In: FURTADO, B; LINS, D. Fazendo Rizoma: Pensamentos Contemporâneos. São Paulo: hedra, 2008, p. 25-44.

RYNGAERT, J.P. Ler o teatro contemporâneo. Trad. Andréa Stahel M. da Silva. São Paulo: Martins Fontes, 1998.

SEDGWICK, E. K. “A epistemologia do armário." Cadernos Pagu, n. 28, 2007, p. 19-54. Disponível em: http:// repositorio.ufsc.br/xmlui/handle/123456789/3503

SILVA, L. "Memória histórica na dramaturgia de Tennessee Williams”. Fênix, Uberlândia, v. 2, n. 3, 2005, p. 1-12. Disponível em: https://www.revistafenix.pro.br/revistafenix/article/view/854.

SOLIVA, T. B. “A confraria gay: um estudo sobre a trajetória da Turma OK.” In: GREEN, J.N; QUINALHA, R.; CAETANO, M.; FERNANDES, M. (orgs.) História do movimento LGBT no Brasil, São Paulo: Alameda, 2018. p. 121-136.

SOLIVA, T. B. Sob o signo do glamour: Um estudo sobre homossexualidades, resistência e mudança social. Tese (Doutorado em Antropologia Cultural) - Programa de Pós-Graduação em Sociologia e Antropologia, Instituto de Filosofia e Ciências Sociais, Universidade Federal do Rio de Janeiro, Rio de Janeiro, 2016.

SHAKESPEARE, W. A tragédia do Rei Ricardo II . São Paulo: eBooksBrasil Livraria, sd.

SONTAG, S. “Notes on Camp”. In: A Susan Sontag Reader. London: Penguin Books, 1964.

TOLEDO, L. M.; FLORES, F. T. "O inquietante silêncio no armário em Summer at the lake, de Tenesse Williams.” Revista Diálogos (RevDia), v. 6, n. 2, 2018, p. 32-51. Disponível em: https://periodicoscientificos. ufmt.br/ojs/index.php/revdia/article/view/6572

THÜRLER, D. “Sabedoria é desaprender - notas para a construção de uma política cultural das margens.” SILVA, G.; PUGA, L.; RIOS, Otávio. (orgs.). In: Alfabetização política, relações de poder e cidadania: perspectivas interdisciplinares. Rio de Janeiro: Letra Capital, 2018.

THÜRLER, D.; WOYDA, D. "Os efeitos marginalizadores da heteronormatividade em The boys in the band". Revista Apotheke, v. 6 n. 3, 2020, p. 128-142. Disponível: https://www.revistas.udesc.br/index.php/apotheke/ article/view/19048.

THÜRLER, D.; MATHIEU, B. "A primeira onda da cena travesti no Brasil e a centralidade do corpo em travesti”. Inédito, 2021.

WILLIAMS, T. Mister Paradise e outras peças em um ato. Tradução Grupo Tapa. São Paulo: É Realizações, 2011. 